\title{
Pathoetiology of multiple sclerosis: are we barking up the wrong tree?
}

\author{
Peter K. Stys
}

Address: Department of Clinical Neurosciences, Hotchkiss Brain Institute, University of Calgary, 3330 Hospital Dr. NW, Calgary T2N 4N1, Canada Email: pstys@ucalgary.ca

Fl000Prime Reports 2013, 5:20 (doi:10.12703/P5-20)

This is an open-access article distributed under the terms of the Creative Commons Attribution-Non Commercial License (http://creativecommons.org/licenses/by-nc/3.0/legalcode), which permits unrestricted use, distribution, and reproduction in any medium, provided the original work is properly cited. You may not use this work for commercial purposes.

The electronic version of this article is the complete one and can be found at: http://f $1000 . c o m / p r i m e /$ reports $/ \mathrm{m} / 5 / 20$

\begin{abstract}
Despite a century of intensive investigation, the underlying cause of multiple sclerosis has eluded us. It is clear that there exists a prominent progressive degenerative phenotype together with an important autoimmune inflammatory component, and careful histopathological examination always shows, to a greater or lesser degree, concomitant degeneration/demyelination and adaptive $\mathrm{T}$ cell-dependent immune responses. Given this picture, it is difficult, if not impossible, to definitively say whether degeneration or autoimmunity is the initiator of the disease. In this review, I put forward the evidence for and against both models and speculate that, in contrast to the accepted view, it is equally likely that multiple sclerosis may be a degenerative disease that secondarily elicits an autoimmune response, and suggest how this might influence therapeutic approaches.
\end{abstract}

\section{Introduction}

Multiple sclerosis (MS) has been recognized clinically for centuries, and has been intensely investigated histopathologically, genetically, immunologically and clinically since the days of Charcot and Babinski in the latter half of the $19^{\text {th }}$ century [1]. Traditionally considered to be an autoimmune inflammatory demyelinating disorder of the CNS, MS histopathology exhibits prominent inflammation, particularly in the white matter (corpus callosum, subcortical tracts, optic nerve and spinal tracts), consisting of T-cell and macrophage infiltration, with demyelination as a universal finding [2]. "Shadow plaques", where axons exhibit thinned myelin, are considered evidence of repair, with partial remyelination of fibers by oligodendrocytes recruited from endogenous progenitors $[3,4]$. Although inflammatory demyelination is the hallmark of MS, more recent studies indicate that neuronal structures are also highly vulnerable, with neuro-axonal degeneration, together with synaptic pathology, being important features $[5,6]$.

Multiple sclerosis distinguishes itself from most other chronic neurological disorders by its curious fluctuating course, in both space and time; the vast majority of MS patients present with relapsing and remitting attacks of demyelination, precipitating clinical deficits depending on the location, almost always followed by resolution of signs, symptoms and T2-lesions evident on MRI, only to suffer additional attacks affecting different parts of the CNS at various times during the course of the disease. In most patients, this initial inflammatory relapsing-remitting phase of MS is followed a decade or more later by a more chronic progressive phase (secondary progressive MS). For unknown reasons, some patients assume a progressive course from the beginning. Given the strikingly different temporal pattern, some have questioned whether this primary progressive form of MS is a different disease altogether, although most investigators believe it is a less inflammatory, later-presenting variant.

\section{Multiple sclerosis as a primary autoimmune disease \\ Genetics}

Despite a century of intensive investigation, the underlying cause of MS has eluded us. The strikingly inflammatory nature of the relapsing-remitting phase of MS, both on pathological and radiological grounds (gadolinium [Gd]-enhancing lesions), strongly points to 
an autoimmune cause. Oligoclonal IgG is found in thecerebrospinal fluid of most MS patients, further hinting at an immune system that may be targeting CNS epitopes behind the blood-brain barrier. Predisposition to MS exhibits a strong genetic component, with a $25-30 \%$ concordance in mono-zygotic twins, decreasing with the degree of relatedness $[7,8]$. The importance of genetics was further elucidated by many genome-wide association studies pointing to genes related to the immune system as playing a major role. The largest such study recently published [9] revealed a strong and unequivocal association with immunologically relevant genes, particularly those involved in T-cell function. Taken together, clinical experimental data convincingly point to an autoimmune etiology for MS.

\section{Environmental factors}

What might trigger the immune system to mount a recurring assault on the CNS, with a particular focus on the white matter? While genetics play a significant role, it is not a major factor, as in many other inherited neurological disorders where clear gene mutations have been identified. There are additional environmental influences, the most curious of which is a striking latitudinal gradient: the further from the equator a population lives, the higher its prevalence of MS $[10,11]$, though some authors dispute this [12]. Even more curious is the observation that if an individual relocates from a low-prevalence area to a highprevalence region that person assumes the higher risk of developing the disease, but only if he/she moves in the first two decades of life [10]. Why geography should influence MS prevalence is not known, but exposure to sunlight, with attendant differences in vitamin D levels, has been suggested [13,14]. This vitamin is a known immunemodulator that enhances regulatory T-cell function, mediating a shift to a more anti-inflammatory immune response [15]. This has been proposed as an explanation for clinical observations, indicating that the risk of MS is inversely correlated with vitamin D levels [16]. Given that $\mathrm{UV}$ radiation promotes the conversion of precursors into active vitamin D metabolites, and northern regions experience significantly less sunlight than in the south, together, this constitutes a plausible explanation for the observed latitudinal variation of MS prevalence. While intriguing, this proposal is so far unproven, however. Another environmental factor implicated in the pathogenesis of MS is the Epstein-Barr virus (EBV). Patients with a history of symptomatic EBV infection carry a higher risk of developing MS [17], and MS patients have a higher seroprevalence rate for EBV compared with healthy controls, especially children [18]. This association is robust, but the mechanisms are unknown. One proposal is that EBV is a trigger for autoimmune disease in general [19], possibly by infection of autoreactive B lymphocytes [20], or by continuously stimulating strong T-cell responses during persistent infection [21].

\section{Therapy}

Taken together, a large body of evidence paints a compelling picture in favor of MS being an autoimmune disease. Understandably, much effort has been expended to develop therapeutic agents to modulate a presumably dysregulated immune system in the hopes of reducing the inflammatory burden. Animal models have been developed to aid in this effort, designed to mirror the immunopathogenesis of MS. The most common model is experimental autoimmune encephalomyelitis (EAE), where a myelin antigen is injected together with adjuvant to elicit an immune response against the CNS. Inbred mice are commonly used and develop a fairly predictable stereotyped ascending paralysis with robust inflammation especially in the spinal cord. A careful dissection of the immunobiology of MS and its animal models, such as EAE, has spurred the development of a series of antiinflammatory agents in wide clinical use. The drugs are highly effective at reducing the inflammatory burden of this disease, and in some cases eliminate inflammatory relapses almost completely. However, with stronger immune modulation come potentially serious sideeffects. A detailed discussion of MS therapeutics is beyond the scope of this paper, and the reader is instead directed to several recent reviews [22-24].

\section{Nagging discrepancies with this picture}

It would appear from the above discussion that MS may well be a primary autoimmune disease: the histopathology, the mechanisms of current therapeutics and their benefits early in the disease course, clinical laboratory data, together with extensive studies of MS genetics, all point to such a conclusion. Yet after decades of intensive research, we do not know the cause of the disease, we have failed to identify the target CNS autoantigens $[25,26]$, we cannot cure the disease, nor do we have effective treatments for the progressive phase, which one could argue is the more important stage with respect to disability. Moreover, a number of inconsistencies, presented below, raise important questions that must not be ignored. Because MS is a chronic disease that is almost never fatal in the early stages, invariably almost all human neuropathology will reflect months or years of multiple processes and reactions that, with time, may "collapse" into a stereotyped histopathological picture. Such a single histopathological snapshot in time (and, with respect to disease onset, a greatly delayed snapshot at that) may not be representative of the earliest events which could otherwise offer valuable clues to the pathogenesis. 


\section{Pathology}

In contrast to the inflammatory demyelinating pathology of "traditional" MS lesions, careful examination of very early lesions that came to histopathological analysis, through biopsy or autopsy, paints a curiously different picture. In these samples, myelin damage, consisting of subtle expansion of innermost myelin loops or at times including extensive demyelination, is seen with little inflammatory infiltration (see [27] and [28], and references therein). However, others report invariable inflammation in biopsied (and therefore presumably early stage) plaques [29]. The timing of histopathological sampling, with respect to true lesion onset, might explain these discrepancies. It has also become apparent that white matter abnormalities are extensive in the MS brain, even in areas far removed from typical demyelinating plaques. The MS brain seems to harbor a continuity of abnormality ranging from "normal-appearing white matter", to "diffusely abnormal white matter", through to typical demyelinated MS plaques. However, even the more subtly affected brain areas can be abnormal histologically, exhibiting axonopathy, gliosis, demyelination and microglial activation. On detailed MRI examination, these areas exhibit a higher $\mathrm{T} 2$ signal, and abnormalities on magnetization transfer and diffusion tensor imaging. Interestingly, evidence for a T-celldependent adaptive immune response outside of the classical actively demyelinating and highly inflammatory plaques is largely lacking in these areas [30-32], although some investigators report low-grade T cell infiltration even in normal-appearing MS white matter [33]. This hints at a more widespread defect, affecting areas in white and gray matter beyond the typical inflammatory plaques that are the most obvious tip of the pathological iceberg.

\section{Genetics}

With reference to genome-wide association studies alluded to above, the following very reasonable counterargument is presented: why have such studies not identified associations with genes unrelated to immune function? The most parsimonious explanation may be that the root cause of MS is not founded in genetics, only the inflammatory reaction is, hence the strong genetic association with immune genes. However, in light of the significant concordance among monozygotic twins, and if degenerative mechanisms underlie both inflammatory (relapsing-remitting) and primary progressive MS (see below), one would expect to find a non-immune genetic association. The more likely explanation probably relates to study power: even in the very large survey of 10,000 MS patients by Sawcer and co-workers [9], just over 700 primary progressive subjects could be studied; even this number was likely insufficient to detect significant non-immune genetic associations. Having said this, despite the fact that immunologically relevant genes represented the overwhelming majority in this study, the single strongest association implicated the GALC gene, which codes for galactocerebrosidase, an enzyme involved in lysosomal hydrolysis of specific galactolipids, and which, when defective, underlies Krabbe's disease, an inflammatory demyelinating leukodystrophy (see below). The significance of this association is uncertain at this time. An even more recent study found that after selecting MS patients for greater atrophy (and thus presumably for a greater degenerative undertone), this was associated with 5 single nucleotide polymorphisms of the GRIN2A gene that codes for the GluN2A subunit of the NMDA receptor [34]. This suggests a role for deregulation of glutamatergic signaling in the degenerative aspects of progressive MS.

\section{Therapy}

A substantial experience with ever more sophisticated and potent therapeutics is equally informative. Several immune-modulating agents have been developed that are extremely effective at reducing, or almost completely eliminating, inflammation in the MS brain, to the point that relapses are largely prevented. Examples include alemtuzumab, a humanized monoclonal antibody and powerful lymphocyte depletor, which reduces relapses and new MRI lesion formation by $>90 \%[35,36]$. Despite a near-complete elimination of clinical relapses and new MRI lesions, the secondary progressive group continued to accumulate disability and exhibited progressive brain atrophy radiologically. A similar experience was observed with rituximab, which depletes B lymphocytes. This agent significantly reduces relapse rates and Gdenhancing lesions in relapsing-remitting MS patients [37], but again fails to significantly alter the course of progressive disease [38]. To explain this quandary, it has been argued that in progressive MS, inflammation becomes "trapped" behind a closed blood-brain barrier [39], which, in turn, makes the aberrant immune elements inaccessible to systemically administered therapeutic agents (particularly antibodies or other larger molecules). However, experience with immune therapy for Alzheimer's disease, for example, indicates that passive administration of humanized monoclonal antibodies (mirroring the strategies in MS) is effective in clearing brain amyloid, presumably by entry of these antibodies across the blood brain barrier [40] in a disease that has decidedly little inflammation to begin with. Therefore, one could surmise that the blood-brainbarrier in the non-inflamed progressive MS brain would also be permeable enough to such antibodies so they could access any "trapped" immune cells. 
Autologous haematopoietic stem-cell transplantation has also been attempted in more aggressive MS cases, with the goal of resetting the immune system and permanently eliminating the offending immune elements [41]. This therapy is successful in completely abrogating inflammatory activity in the MS brain, but it is generally thought that this option is most effective in particularly inflammatory forms of the disease. The corollary is that less inflammatory later-progressive stages would not respond to transplantation any more than they respond to potent immune modulators, as noted above. Having said this, now that patients with longer post-transplant times have been followed, it appears that the rate of brain atrophy is nevertheless reduced [41], indicating that inflammation likely drives atrophy to a certain extent. This should not be surprising given the very cytotoxic milieu of inflammatory foci with high levels of glutamate, nitric oxide and various cytokines all known to irreversibly kill various CNS cells types [42-45]. In the end though, after decades of intensive investigation and experience with ever more advanced immune-targeted therapeutics, we still cannot answer the key question pertaining to MS pathoetiology: does inflammation begin for some unknown reason, and then promote chronic degeneration? Or does a primary degeneration secondarily trigger persistent and fluctuating inflammation, which then may feed back to further drive degeneration by virtue of the cytotoxins that are released? Conventional thinking favors the former scenario (the "outside-in" model where a systemic immune defect targets the CNS; Fig. 1); the next section will attempt to "reconstruct" MS without any a priori assumptions about etiology, arguing that all available data are equally consistent with the converse "insideout" model [46].

\section{Reconstructing MS: a thought experiment}

Let us adopt an unconventional position and hypothesize that MS is a degenerative disorder at its root, much like Alzheimer's, Parkinson's and many other progressive degenerative CNS disorders of unknown cause. As with most such diseases, the pathological process likely begins years or possibly decades before the initial clinical presentation. In support of this, adolescents with MS have not only a significantly reduced brain volume but also a reduced head size [47], implying that the disease likely began many years earlier while the skull was still growing. Whether this applies to adult MS will require further investigation. Unlike other neurodegenerative disorders where certain cortical regions or nuclei appear to be most affected, in our hypothetical model of MS we will assume that the myelinating unit (the oligodendrocyte and its myelin sheaths) is the main primary target. This conjecture is based on detailed pathological
Figure I. Diagram illustrating the two competing models of MS pathogenesis

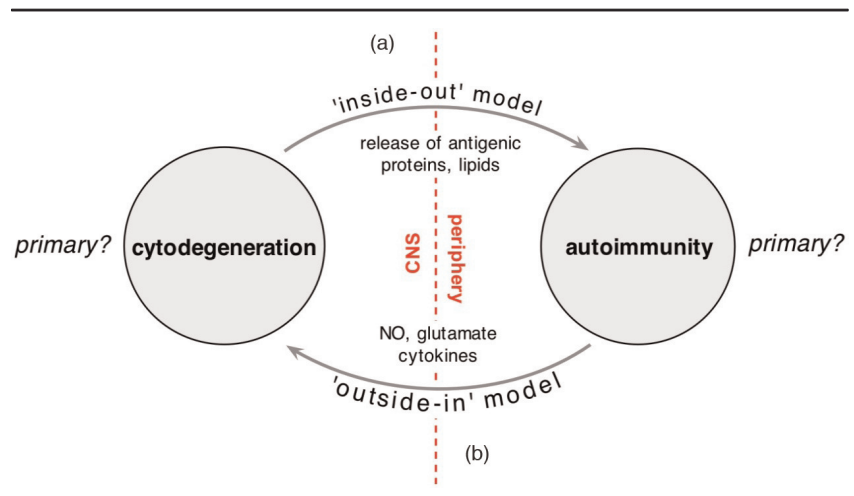

(a) The "inside-out" model favors an as yet unidentified cytodegeneration, possibly targeting the myelin-oligodendrocyte complex, leading to release of highly antigenic myelin debris. With time, the immunologically predisposed host mounts a secondary immune reaction to this material, of variable intensity, culminating in a clinical phenotype characterized by recurrent inflammatory attacks on a background of progressive degeneration, atrophy and accumulation of disability. The inflammation responds to antiinflammatory therapy, whereas the degenerative process predictably does not. (b) The alternate model that is the currently accepted view places autoimmunity at the root of the process, driving degeneration, which then somehow becomes independent of inflammation and continues in the progressive phase of the disease. Regardless, what is certain is that all evidence implicates degeneration and inflammation as important players in the final genesis of early and late MS. The key question that should investigated however, is which process is the initial instigator? (Modified from [46]).

examination of very early MS lesions and biopsy data (see above), where these elements seem to be affected first and in isolation, before inflammatory reactions and neuro-axonal dropout set in. The cause of this cytodegeneration focused on the myelinating unit is of course unknown, but so are the causes of sporadic Alzheimer's, Parkinson's or multiple system atrophy, the latter being a specific degeneration of oligodendrocytes [48]. With the gradual disappearance of oligodendrocytes and ensheathing myelin, both in the brain and spinal cord, axons would secondarily start to degenerate, because it is well established that myelination confers an important trophic and metabolic advantage [49,50]. The cellular degeneration would entrain a typical innate inflammatory reaction, consisting of microglial activation and astrogliosis common to most if not all degenerative disorders, together with a predictable progressive atrophy of the brain and spinal cord. Indeed, mutations of genes coding for certain myelin proteins (e.g. proteolipid protein [51]) may present with a clinical picture indistinguishable from primary progressive MS (complete with synthesis of oligoclonal bands in the cerebrospinal fluid), arguing that primary defects 
targeting the myelinating unit, whether genetically coded or environmental, may produce a primary progressive MS-like disease.

At this stage of our thought experiment, we have constructed a disease similar to primary progressive MS. One could argue that this misses the point, because the majority ( $>85 \%$ ) of MS patients do not present with progressive disease, but with relapsing-remitting inflammatory MS. For reasons that are not well understood, myelin is highly encephalitogenic, particularly after specific biochemical modification, such as citrullination [52-54]. In fact, of the five major CNS antigens that elicit a pathological immune response in mice (myelin basic protein, proteolipid protein, myelin oligodendrocyte glycoprotein, myelin-associated glycoprotein and S-100 protein [55]), four are major myelin proteins. It stands to reason that our hypothetical model of progressive MS will include a continuous and chronic shedding of myelin antigens, possibly processed in specific ways to render the components even more antigenic (e.g. citrullination of myelin basic protein by myelin-resident Ca-dependent deiminases [52]). We now add a second key ingredient to the model: a dysregulated immune system directed mainly at myelin antigens (those provided by the primary oligo-myelinic degeneration described above), whose level of overactivity is highly variable, additionally influenced by a myriad of environmental and genetic factors. The resulting disease will thus be a "convolution" of a primary oligo-myelinic cytodegeneration and a variable level of dysimmunity [46] (Fig. 2). Although such a combination of two processes is purely speculative in the case of MS, there is precedent in other conditions. For instance, Harding's disease results from a mutation of the mitochondrial genome that results in optic neuropathy similar to Leber's hereditary optic neuropathy, but with more widespread involvement of the CNS white matter, together with inflammatory relapses and remissions and, at times, laboratory and radiological findings indistinguishable from inflammatory MS [56]. Either these cases are chance associations between a mitochondrial defect and MS (highly unlikely given the prevalence rates of Leber's and MS: Harding's is 50 times more common than what would be expected by chance associations of Leber's and MS, if Harding's were simply such an association, which strongly suggests that Harding's is not such a chance association, but a mitochondrial disorder morphed into an MS-like disease by a dysregulated immune system), or, instead, Harding's syndrome is an example of a welldefined biochemical defect of energy metabolism (a typical Leber's patient) "convolved" in the occasional patient additionally harboring an immune defect that changes the phenotype to one that resembles
Figure 2. Model proposing that MS is a convolution of two important processes
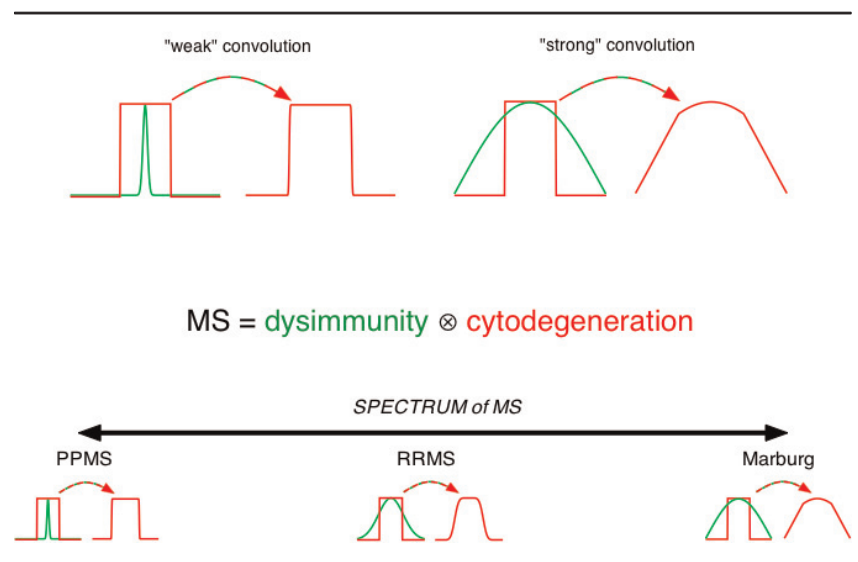

Convolution is a mathematical "smearing" of two functions: if the convolving function is weak (narrow green function, top left), the result is similar to the input (red). If on the other hand the convolution is very strong, the output may not resemble the input at all (red, top right). The curiously broad spectrum of MS phenotypes may be explained by such a variable convolution of two processes: at its root, MS may consist of a monotonically progressive degenerative disease, much like Alzheimer's and Parkinson's.

With a weak immune influence, the result is progressive MS which harbors little inflammation and progresses much like other neurodegenerative disorders. At the other extreme, a very aggressive inflammatory reaction produces a highly inflammatory condition bearing little resemblance to the putative underlying slowly progressive disorder. As it turns out, the majority of MS falls somewhere in the middle of this spectrum. This model presupposes that the underlying degeneration is fairly stereotyped, with the heterogeneity mainly arising from the variable dysimmunity. One important corollary is that, if MS is indeed a convolution of two processes,

epidemiological, pathological, and genetic studies may be reflective of only one, and not the other, component. Admittedly, over the years focus has been overwhelmingly placed on the immunobiology of MS, therefore most data pertain to the green function, with little insight into the red function which, as the common thread in the above model, may lie at the root of this disease.

inflammatory MS, complete with T-cell-mediated inflammatory demyelination [57]. Similarly, Krabbe's globoid cell leukodystrophy, caused by galactocerebrosidegalactosidase mutations, also exhibits profound demyelination and perivascular T-cell infiltrates in the white matter [25,58]. A final example is adrenoleukodystrophy, an X-linked genetic defect of peroxisomal very long chain fatty acid metabolism. Widespread inflammatory demyelination, including perivascular lymphocytic cuffing reminiscent of MS pathology, and Gd-enhancing white matter lesions are characteristic [59]. Milder forms in female carriers can be clinically very similar to MS $[60,61]$. While the author recognizes the fundamental differences between adrenoleukodystrophy and MS, this leukodystrophy and its variants are particularly instructive on a number of levels. The majority of adrenoleukodystrophy 
patients exhibit oligoclonal expansion of $\mathrm{T}$ cells [62], much like the oligoclonal $\mathrm{T}$ cell expansion found in MS brain [63]. Such T cell expansion in MS lesions is interpreted as a sign of antigen-specific activation, and therefore evidence of an autoimmune process [64]; this conclusion is undoubtedly correct. However, the real question should be: is this evidence for a primary autoimmune process, or is the observed autoimmunity secondary to another process that releases highly antigenic myelin fragments? The fact that similar oligoclonal T cell expansions occur in adrenoleukodystrophy with an unequivocally established metabolic defect causing degeneration of myelin argues against an autoimmune condition that is primary; such a $\mathrm{T}$ cell response is certainly consistent with autoimmunity, but this could as easily be secondary to release of autoantigens by a degenerative process in a host whose immune system is primed to react to such material. Nor is the observation of low-grade diffuse $T$ cell infiltration of normal-appearing white matter in MS [63] evidence of a primary autoimmune condition, as a similar infiltration is again seen in histologically otherwise normal (but biochemically abnormal) white matter distant from focal adrenoleukodystrophy lesions [65]. Curiously, the same genetic defect that causes adrenoleukodystrophy in some patients can also result in a later-presenting non-inflammatory progressive adrenomyeloneuropathy, even in members of the same family [66]. Detailed pathological examination of the latter condition reveals a minimal, mainly perivascular, lymphocytic inflammation (though a prominent microgliosis is invariable) on a background of prominent axonal degeneration (rather than demyelination) of the spinal cord; nevertheless, even these patients have some degree of cerebral white matter pathology [67] (this point is germane to the speculation below). Why the same gene defect should cause such variable phenotypes is unknown. This prompts an intriguing speculation that may apply to MS as well: all male adrenoleukodystrophy patients would have progressed along the more indolent degenerative course characteristic of adrenomyeloneuropathy, but, in a substantial proportion of these patients, the immune system is primed to react to myelin autoantigens released because of the metabolic defect, transforming a laterpresenting more indolent phenotype, into a severe childhood neuroinflammatory illness causing death within a few years of onset. In addition, because the severelyaffected patients usually die young, the opportunity never arises for the delayed adrenomyeloneuropathy to develop. The possible parallel between this argument pertaining to a known neurometabolic disease and MS (youngerpresenting inflammatory relapsing-remitting phase of MS vs. later-presenting progressive MS), is interesting. Speculations aside, at a minimum, the contrast between adrenoleukodystrophy and adrenomyeloneuropathy serves as a poignant example of myelin degeneration entraining a very vigorous lymphocytic inflammatory response in the former, whereas an axonal degeneration in the latter does not, emphasizing the curious but pathophysiologically important encephalitogenic properties of degenerating myelin that may also program much of the early inflammatory MS phenotype.

Interestingly, not all metabolic leukodystrophies resulting in profound dysmyelination evoke an inflammatory response (e.g. metachromatic leukodystrophy [68]). A particularly striking example is vanishing white matter disease, now known to be caused by a mutation in the gene coding for eukaryotic translation initiation factor eIF2B in most cases [69]. Despite profound degeneration of white matter, affected areas are completely devoid of $\mathrm{T}$ or B cell infiltration [70]. It is thought that glial cells (in particular the oligodendrocyte) are the main target of this genetic defect; the resulting disconnection between severe white matter degeneration and inflammation parallels that seen with primary destruction of oligodendrocytes by diphtheria toxin receptor in transgenic mice, and may be instructive vis-à-vis which subcellular elements may be key for triggering immune reactions (see below). This raises the intriguing possibility that degeneration of myelin per se is necessary, but not sufficient, to trigger the primed immune system; it may be that myelin antigens may need to be processed and degraded in specific ways (see below). Clearly, in the above examples, the detailed radiological and pathological features are not identical to those of MS, nor should we expect them to be since the underlying pathophysiological defects are likely quite different. The main point, however, is that there is precedent for well-defined biochemical defects to result in progressive demyelinating white matter pathology, together with a secondary inflammatory reaction, that bears strong resemblance to that seen in MS.

Let us now predict how a convolution of a primary oligomyelinic degeneration with a dysregulated immune system would alter the phenotype of a "pure" primary progressive MS-like disease. First, because there is a concomitant inflammatory assault on the CNS that causes additional damage, the first clinical presentation may occur years earlier than the prototypical primary progressive MS-like disease (as with many degenerative diseases, cellular dropout precedes clinical threshold by many years; an additional inflammatory attack, targeting an eloquent region of the CNS may temporarily bring clinical signs and symptoms above this clinical threshold, until the inflammation subsides). Second, if the dysimmunity is variable in intensity, and fluctuates over time, the result will be a variable relapsing-remitting 
course, reflecting inflammatory flares, at times severe and frequent, at other times (and in other patients) less frequent and more benign, that respond well to antiinflammatory treatments. Immune modulators would be expected to be highly effective in reducing or eliminating these flares, though the underlying degeneration, which is not dependent on a dysregulated immune system, but is instead due to a putative biochemical defect (such as in Harding's or adrenoleukodystrophy), would continue to progress despite best therapeutic anti-inflammatory efforts. Conversely, with a constant dysimmune predilection, a variable degree and rate of cytodegeneration, may, in turn, provoke a more frequent and more aggressive inflammatory course, which may be misinterpreted as the inflammation primarily driving disease progression. There is also precedent for variable rates of degeneration, as Alzheimer's and Parkinson's diseases may present at variable ages and progress at very different rates. Admittedly, given the known deleterious effects of repeated inflammatory flares, the resulting cellular destruction from the toxic inflammatory milieu, and the limited ability of the CNS to regenerate, it stands to reason that suppressing the immune system may, in fact, play a beneficial, albeit limited, role in mitigating progression, but only in those patients where the inflammatory component in the convolution is substantial; in purely degenerative cases, immune suppression would be expected to be ineffective. It also stands to reason that since myelin is a potent autoantigen, as discussed above, shedding of myelin debris would entrain an immune response more often than not; the corollary is that in most cases the convolution of degeneration and dysimmunity would be strong (i.e. the phenotype would be inflammatory), even though the fundamental defect is still an undefined biochemical flaw in our hypothetical disorder. This corollary has a fundamentally important implication: studying such "typical" hypothetical MS patients would thus bias the samples in favor of those where the component of dysimmunity is prominent. Any genetic and/or environmental risk associations that emerge from such studies may, therefore, reflect not the underlying degeneration which we have selected as the fundamental etiology of our hypothetical disease, but may instead reflect the aberrant immune response to this degeneration, and never shed light on the underlying cause that we decided underpins our hypothetical disorder.

Examining our experience with MS, one notes striking parallels with the scenario presented above. Although on the surface the evidence accumulated to date, from epidemiological, immunological, pathologi$\mathrm{cal}$, and genetic studies, together with clinical therapeutic experience, all point to a primary immune-mediated disease in a compelling way (indeed the hypothetical model, as constructed above, would result in much the same evidence, yet it was deliberately devised to be rooted in a primary degeneration), a potential shortcoming of this argument may be the following: if the above model is correct, why don't other more common white matter degenerations result in MS? For instance, stroke is not uncommon in young adults, and almost invariably results in white matter damage. Alzheimer's also frequently results in white matter degeneration [71], and presumably releases myelin debris. The simple answer may be that our hypothetical model is wrong. On the other hand, such discrepancies may instead be instructive. Stroke is an acute self-limited insult, causing extensive destruction of the affected parenchymal volume with a significant necrotic component. In order to elicit a chronic immune reaction, it is possible that myelin antigens may instead need to be processed and released in more subtle ways, which acutely ischemic conditions do not promote. Alzheimer's disease results in chronic white matter degeneration, much like MS, yet an inflammatory MS-like disorder is not triggered in this situation. One explanation may be "immune senescence", whereby immune responsiveness is known to wane with age [72]. The decreasing intensity of lymphocytic infiltration with age in the MS brain [33], despite continuing demyelination and neurodegeneration, is consistent with this suggestion. A more intriguing possibility may be a direct anti-inflammatory effect of amyloid beta $(\mathrm{A} \beta)$, known to be generated in excess in Alzheimer's brain [73]. Steinman and co-workers showed that administering exogenous $A \beta$ to mice significantly reduced the severity of EAE [74], a model that recapitulates the inflammatory reaction to myelin antigens.

Finally, a number of animal models of white matter degeneration, resulting in different outcomes, are also instructive. Killing oligodendrocytes using a geneticallyencoded diphtheria toxin receptor results in widespread demyelination and death of these cells; however, there is no adaptive immune response, despite deliberate stimulation of the immune system [75]. In contrast, overexpression of proteolipid protein, the major protein of CNS myelin, resulted in a spontaneous immunemediated demyelination, without any additional activation of the immune system [76]. Another example is the Pex5 knock-out mouse, resulting in absence of functional peroxisomes in oligodendrocytes, causing widespread demyelination and axonal degeneration [77]. Histopathology of this knockout mouse reveals pronounced infiltration in the CNS, mainly by CD8+ T cells, just as in human MS [25]. Finally, deletion of the Cnp1 gene coding for the myelin protein $2^{\prime}$-3'-cyclic 
nucleotide-3'-phosphodiesterase induces selective white matter degeneration, together with a vigorous spontaneous CD8 T-cell response [78]. Although these are quite different models, one may be tempted to speculate that a defect of the myelin sheath per se (possibly resulting in a specific biochemical alteration rendering the degenerated myelin even more antigenic [52], and/or involving myelin lipids [25]), rather than of the parent oligodendrocyte, may be a key factor in determining whether an adaptive immune response will be raised in the susceptible host, or not, thereby transforming a fundamentally monotonically progressive degenerative disease into a fluctuating inflammatory disorder masquerading as a primary autoimmune condition. Indeed, the mode of cell death may be critical: diphtheria toxin receptormediated cell death proceeds by apoptosis [79], which is a programmed and well orchestrated sequence of events leading to the cell's removal. Under these conditions, it is likely that destructive Ca-dependent enzymes, such as calpains and citrulline-generating deiminases (typically associated with necrotic cell death), do not play a major role, and therefore myelin breakdown fragments may not have been processed in specific ways to render the material encephalitogenic. The fact that very early MS lesions exhibit apoptotic oligodendroglia [80] may simply indicate their reaction to an unidentified, non-immune-related toxic insult that initiates the demyelinating lesion, possibly directly targeting the oligodendroglial cell processes and/or myelin sheaths and their receptors $[81,82]$.

\section{Conclusion and future directions}

What is clear from an objective look at human MS is that there exists a prominent progressive degenerative phenotype together with an important autoimmune inflammatory component. This is indisputable. Also, careful histopathological examination always shows, to a greater or lesser degree, concomitant degeneration/demyelination and adaptive $\mathrm{T}$ cell-dependent immune responses, making it difficult, if not impossible, to definitively answer the question of which process was the initiator. Regardless, it follows that such an invariable connection between axonal-oligodendrocytic-myelinic degeneration and inflammation makes the inside-out model no less likely than the outside-in; it appears that myelin degeneration (see above) is such a potent immuneinducing stimulus that one will never observe one without the other, at least not in human tissue where sequential observation from the very earliest beginnings of pathology is impossible. Nonetheless, persistent inflammation likely causes additional damage to the CNS, over and above what would have accrued from the underlying degeneration alone. In the author's opinion, the critical question at this time is not whether degeneration or inflammation is more important, but rather: is the obvious autoimmunity/inflammation in MS primary, i.e. causative, or is it reactive to some underlying degenerative process? This question is, at the same time, fundamentally important, as it will alter our understanding of MS at a mechanistic level, and - more importantly for patients - guide future therapeutic design in a completely different direction. Based on a series of observations from MS patients and related conditions, in this paper I have argued in favor of the 'inside-out' model, where an underlying cytodegenerative process secondarily entrains (and very quickly at that it seems) innate and adaptive immune responses, though it should be stressed that such arguments are purely speculative at the moment. However, if this scenario is correct and reflects the true pathoetiology of $\mathrm{MS}$, it follows that our focus on autoimmune animal models will elucidate the inflammatory reaction to the underlying degeneration, rather than reflecting the underlying cause. Therapeutics that stem from such an approach may, therefore, be limited as they will fail to address the root cause, whatever this turns out to be. Moreover, by studying the epidemiology, environmental influences and genetics of the commonest form of MS (relapsing-remitting MS), which was the logical initial approach, we may be, once again, inadvertently generating data on the immunobiology of the inflammatory reaction to the underlying disease process. Instead, it may be time to target our efforts on primary progressive MS, which may be the purest form of MS, even though paradoxically it constitutes the minority of MS presentations. In the end, the hope is that this approach will yield an incisive new data set that will be complementary to the vast knowledge of MS immunobiology, paving the way for even more effective therapies targeting both components of this complex convolution.

\section{Abbreviations}

CNS, central nervous system; EAE, experimental autoimmune encephalomyelitis; EBV, Epstein Barr virus; MRI, magnetic resonance imaging; MS, multiple sclerosis.

\section{Disclosures}

The author declares that he has no disclosures.

\section{Acknowledgments}

The author is supported by an AI-HS Scientist award. Work in the author's laboratory is supported in part by the MS Society of Canada, CIHR and Canada Research Chairs. 


\section{References}

I. Kornek B, Lassmann H: Axonal pathology in multiple sclerosis. A historical note. Brain Pathol 1999, 9:65I-6.

2. Lassmann $\mathrm{H}$ : Multiple sclerosis pathology: evolution of pathogenetic concepts. Brain Pathol 2005, I 5:217-22.

3. Prineas JW, Barnard RO, Kwon EE, Sharer LR, Cho ES: Multiple sclerosis: remyelination of nascent lesions. Ann Neurol 1993, 33:|37-5|.

4. Patrikios P, Stadelmann C, Kutzelnigg A, Rauschka H, Schmidbauer M, Laursen H, Sorensen PS, Brück W, Lucchinetti C, Lassmann H: Remyelination is extensive in a subset of multiple sclerosis patients. Brain 2006, I 29:3165-72.

5. Peterson JW, Trapp BD: Neuropathobiology of multiple sclerosis. Neurol Clin 2005, 23:107-29, vi-vii.

\section{FlOOOPrime}

\section{RECOMMENDED}

6. Geurts JJG, Calabrese M, Fisher E, Rudick RA: Measurement and clinical effect of grey matter pathology in multiple sclerosis. Lancet Neurol 2012, I I:1082-92.

\section{FlOOOPrime}

\section{RECOMMENDED}

7. Hawkes $\mathrm{CH}$, Macgregor AJ: Twin studies and the heritability of MS: a conclusion. Mult Scler 2009, I 5:66I-7.

8. Ebers GC: Environmental factors and multiple sclerosis. Lancet Neurol 2008, 7:268-77.

9. Sawcer S, Hellenthal G, Pirinen M, Spencer CCA, Patsopoulos NA, Moutsianas L, Dilthey A, Su Z, Freeman C, Hunt SE, Edkins S, Gray E, Booth DR, Potter SC, Goris A, Band G, Oturai AB, Strange A, Saarela J, Bellenguez C, Fontaine B, Gillman M, Hemmer B, Gwilliam R, Zipp F, Jayakumar A, Martin R, Leslie S, Hawkins S, Giannoulatou E, et al.: Genetic risk and a primary role for cell-mediated immune mechanisms in multiple sclerosis. Nature 201 I, 476:214-9.

\section{FlOOOPrime \\ RECOMMENDED}

10. Kurtzke JF: Epidemiology and etiology of multiple sclerosis. Phys Med Rehabil Clin N Am 2005, I6:327-49.

II. Simpson S, Blizzard L, Otahal P, van der Mei I, Taylor B: Latitude is significantly associated with the prevalence of multiple sclerosis: a meta-analysis. J Neurol Neurosurg Psychiatr 201 I, 82: I I32-4 I.

12. Koch-Henriksen N, Sørensen PS: The changing demographic pattern of multiple sclerosis epidemiology. Lancet Neurol 2010 , 9:520-32.

13. Ascherio A, Munger KL: Environmental risk factors for multiple sclerosis. Part II: Noninfectious factors. Ann Neurol 2007, 6 I :504- I 3.

FlOOOPrime

14. Agrawal SM, Yong VW: Immunopathogenesis of multiple sclerosis. Int Rev Neurobiol 2007, 79:99-I 26

\section{FlOOOPrime \\ RECOMMENDED}

15. Smolders J, Damoiseaux J, Menheere P, Hupperts R: Vitamin D as an immune modulator in multiple sclerosis, a review. J Neuroimmunol 2008, 194:7-17.

\section{FIOOOPrime}

16. Weinstock-Guttman B, Mehta BK, Ramanathan M, Karmon Y, Henson LJ, Halper J, Riskind P: Vitamin D and multiple sclerosis. Neurologist 2012, I 8: I79-83.

\section{FlOOOPrime
RECOMMENDED}

17. Thacker EL, Mirzaei F, Ascherio A: Infectious mononucleosis and risk for multiple sclerosis: a meta-analysis. Ann Neurol 2006, 59:499-503.
18. Banwell B, Krupp L, Kennedy J, Tellier R, Tenembaum S, Ness J, Belman A, Boiko A, Bykova O, Waubant E, Mah JK, Stoian C, Kremenchutzky M, Bardini MR, Ruggieri M, Rensel M, Hahn J, Weinstock-Guttman B, Yeh EA, Farrell K, Freedman M, livanainen M, Sevon M, Bhan V, Dilenge M, Stephens D, Bar-Or A: Clinical features and viral serologies in children with multiple sclerosis: a multinational observational study. Lancet Neurol 2007, 6:773-8I.

\section{FlOOOPrime
RECOMMENDED}

19. Evans AS: E.B. virus antibody in systemic lupus erythematosus. Lancet 197I, I:1023-4.

20. Pender MP: Infection of autoreactive B lymphocytes with EBV, causing chronic autoimmune diseases. Trends Immunol 2003, 24:584-8.

21. Giovannoni G, Cutter GR, Lunemann J, Martin R, Münz C, Sriram S, Steiner I, Hammerschlag MR, Gaydos CA: Infectious causes of multiple sclerosis. Lancet Neurol 2006, 5:887-94.

\section{FIOOOPrime
RECOMMENDED}

22. Kieseier $B C$ : The mechanism of action of interferon- $\beta$ in relapsing multiple sclerosis. CNS Drugs 20I I, 25:49I-502.

23. Fox EJ, Rhoades RW: New treatments and treatment goals for patients with relapsing-remitting multiple sclerosis. Curr Opin Neurol 20I2, 25:SII-9.

24. Marta M, Giovannoni G: Disease modifying drugs in multiple sclerosis: mechanisms of action and new drugs in the horizon. CNS Neurol Disord Drug Targets 2012, I I:610-23.

25. Friese MA, Fugger L: Pathogenic CD8(+) $\mathbf{T}$ cells in multiple sclerosis. Ann Neurol 2009, 66: |32-4I.

26. Wootla B, Eriguchi $M$, Rodriguez $M$ : Is multiple sclerosis an autoimmune disease? Autoimmune Dis 2012, $2012: 969657$.

27. Rodriguez M, Scheithauer B: Ultrastructure of multiple sclerosis. Ultrastruct Pathol 1994, 18:3-I3.

\section{FlOOPPrime}

RECOMMENDED

28. Prineas J: Pathology of the early lesion in multiple sclerosis. Hum Pathol 1975, 6:531-54.

29. Brück W, Schmied M, Suchanek G, Brück $Y$, Breitschopf H, Poser S Piddlesden S, Lassmann $\mathrm{H}$ : Oligodendrocytes in the early course of multiple sclerosis. Ann Neurol 1994, 35:65-73.

30. Trapp BD, Peterson J, Ransohoff RM, Rudick R, Mörk S, Bö L: Axonal transection in the lesions of multiple sclerosis. $N$ Engl J Med 1998, 338:278-85.

31. Seewann A, Vrenken $H$, van der Valk $P$, Blezer ELA, Knol DL, Castelijns JA, Polman CH, Pouwels PJW, Barkhof F, Geurts JJG: Diffusely abnormal white matter in chronic multiple sclerosis: imaging and histopathologic analysis. Arch Neurol 2009 , 66:601-9.

32. Filippi M, Rocca MA, Barkhof F, Brück W, Chen JT, Comi G, DeLuca G, Stefano N de, Erickson BJ, Evangelou N, Fazekas F, Geurts JJG, Lucchinetti C, Miller DH, Pelletier D, Popescu BFG, Lassmann $\mathrm{H}$ : Association between pathological and MRI findings in multiple sclerosis. Lancet Neurol 2012, I I:349-60.

\section{FlOOOPrime \\ RECOMMENDED}

33. Frischer JM, Bramow S, Dal-Bianco A, Lucchinetti CF, Rauschka $H$ Schmidbauer M, Laursen H, Sorensen PS, Lassmann H: The relation between inflammation and neurodegeneration in multiple sclerosis brains. Brain 2009, I32: | |75-89.

\section{FlOOOPrime}

34. Strijbis EMM, Inkster B, Vounou M, Naegelin Y, Kappos L, Radue E, Matthews PM, Uitdehaag BMI, Barkhof F, Polman CH, Montana G, Geurts JJG: Glutamate gene polymorphisms predict brain volumes in multiple sclerosis. Mult Scler 2013, 19:281-8. 
35. Coles AJ, Wing MG, Molyneux P, Paolillo A, Davie CM, Hale G, Miller D, Waldmann $H$, Compston A: Monoclonal antibody treatment exposes three mechanisms underlying the clinical course of multiple sclerosis. Ann Neurol 1999, 46:296-304.

\section{FIOOOPrime}

36. Jones JL, Coles AJ: Spotlight on alemtuzumab. Int MS J 2009, 16:77-81.

37. Hauser SL, Waubant E, Arnold DL, Vollmer T, Antel J, Fox RJ, Bar-Or A, Panzara M, Sarkar N, Agarwal S, Langer-Gould A, Smith $\mathrm{CH}$ : B-cell depletion with rituximab in relapsingremitting multiple sclerosis. N Engl J Med 2008, 358:676-88.

\section{FlOOOPrime}

\section{RECOMMENDED}

38. Hawker K, O'Connor P, Freedman MS, Calabresi PA, Antel J, Simon J, Hauser S, Waubant E, Vollmer T, Panitch H, Zhang J, Chin P, Smith $\mathrm{CH}$ : Rituximab in patients with primary progressive multiple sclerosis: results of a randomized double-blind placebo-controlled multicenter trial. Ann Neurol 2009, 66:460-7I.

\section{FlOOOPrime}

\section{RECOMMENDED}

39. Hochmeister S, Grundtner R, Bauer J, Engelhardt B, Lyck R, Gordon G, Korosec T, Kutzelnigg A, Berger JJ, Bradl M, Bittner RE, Lassmann H: Dysferlin is a new marker for leaky brain blood vessels in multiple sclerosis. J Neuropathol Exp Neurol 2006, 65:855-65.

40. Lemere CA, Masliah E: Can Alzheimer disease be prevented by amyloid-beta immunotherapy? Nat Rev Neurol 2010, 6:108-19.

41. Mancardi G, Saccardi R: Autologous haematopoietic stem-cell transplantation in multiple sclerosis. Lancet Neurol 2008, 7: 626-36.

\section{FlOOOPrime}

42. Smith $\mathrm{KJ}$, Lassmann $\mathrm{H}$ : The role of nitric oxide in multiple sclerosis. Lancet Neurol 2002, I:232-4I.

43. Howe CL, Adelson JD, Rodriguez M: Absence of perforin expression confers axonal protection despite demyelination. Neurobiol Dis 2007, 25:354-9.

44. Siffrin V, Vogt J, Radbruch H, Nitsch R, Zipp F: Multiple sclerosis candidate mechanisms underlying CNS atrophy. Trends Neurosci 2010, 33:202-10.

45. Matute C: Glutamate and ATP signalling in white matter pathology. J Anat 20I I, 21 9:53-64.

46. Stys PK, Zamponi GW, van Minnen J, Geurts JJG: Will the real multiple sclerosis please stand up? Nat Rev Neurosci 2012, 13:507-|4.

47. Kerbrat A, Aubert-Broche B, Fonov V, Narayanan S, Sled JG, Arnold DA, Banwell B, Collins DL: Reduced head and brain size for age and disproportionately smaller thalami in child-onset MS. Neurology 2012, 78:194-201.

\section{FlOOOPrime} RECOMMENDED

48. Wenning GK, Stefanova N, Jellinger KA, Poewe $W$, Schlossmacher MG: Multiple system atrophy: a primary oligodendrogliopathy. Ann Neurol 2008, 64:239-46.

49. Nave K, Trapp BD: Axon-glial signaling and the glial support of axon function. Annu Rev Neurosci 2008, 31:535-61.

50. Nave K: Myelination and support of axonal integrity by glia. Nature 2010, 468:244-52.

5I. Warshawsky I, Rudick RA, Staugaitis SM, Natowicz MR: Primary progressive multiple sclerosis as a phenotype of a PLPI gene mutation. Ann Neurol 2005, 58:470-3.

52. Cao L, Sun D, Whitaker JN: Citrullinated myelin basic protein induces experimental autoimmune encephalomyelitis in Lewis rats through a diverse $\mathbf{T}$ cell repertoire. J Neuroimmunol 1998, 88:21-9.
53. Moscarello MA, Mastronardi FG, Wood DD: The role of citrullinated proteins suggests a novel mechanism in the pathogenesis of multiple sclerosis. Neurochem Res 2007, 32:25I-6.

\section{FlOOOPrime}

\section{RECOMMENDED}

54. Kanter JL, Narayana S, Ho PP, Catz I, Warren KG, Sobel RA, Steinman L, Robinson WH: Lipid microarrays identify key mediators of autoimmune brain inflammation. Nat Med 2006, 12:138-43.

\section{FIOOOPrime
RECOMMENDED}

55. Sriram S, Steiner I: Experimental allergic encephalomyelitis: a misleading model of multiple sclerosis. Ann Neurol 2005, 58:939-45.

\section{FlOOOPrime
RECOMMENDED}

56. Palace J: Multiple sclerosis associated with Leber's Hereditary Optic Neuropathy. J Neurol Sci 2009, 286:24-7.

\section{FlOOOPrime}

RECOMMENDED

57. Kovács GG, Höftberger R, Majtényi K, Horváth R, Barsi P, Komoly S, Lassmann H, Budka H, Jakab G: Neuropathology of white matter disease in Leber's hereditary optic neuropathy. Brain 2005, I28:35-4I.

58. Itoh M, Hayashi M, Fujioka $Y$, Nagashima $K$, Morimatsu $Y$, Matsuyama H: Immunohistological study of globoid cell leukodystrophy. Brain Dev 2002, 24:284-90.

\section{FlOOOPrime
RECOMMENDED}

59. Moser HW: Adrenoleukodystrophy: phenotype, genetics, pathogenesis and therapy. Brain 1997, $120(\mathrm{Pt} 8): 1485-508$.

60. Stöckler S, Millner M, Molzer B, Ebner F, Körner E, Moser HW: Multiple sclerosis-like syndrome in a woman heterozygous for adrenoleukodystrophy. Eur Neurol 1993, 33:390-2.

6I. Dooley JM, Wright BA: Adrenoleukodystrophy mimicking multiple sclerosis. Can J Neurol Sci 1985, 12:73-4.

62. Picard F, Guidoux S, Martin T, Aubourg P, Pasquali J: T-cell receptor Vbeta gene usage in CSF lymphocytes in X-linked adrenoleukodystrophy. J Mol Recognit 2005, I8:254-6I.

\section{FlOOOPrime} RECOMMENDED

63. Junker A, Ivanidze J, Malotka J, Eiglmeier I, Lassmann $\mathrm{H}$, Wekerle $\mathrm{H}$, Meinl E, Hohlfeld R, Dornmair K: Multiple sclerosis: T-cell receptor expression in distinct brain regions. Brain 2007, 130:2789-99.

64. Babbe H, Roers A, Waisman A, Lassmann H, Goebels N, Hohlfeld R, Friese M, Schröder R, Deckert M, Schmidt S, Ravid R, Rajewsky K: Clonal expansions of CD8(+) $\mathrm{T}$ cells dominate the $\mathrm{T}$ cell infiltrate in active multiple sclerosis lesions as shown by micromanipulation and single cell polymerase chain reaction. J Exp Med 2000, 192:393-404.

65. Ito M, Blumberg BM, Mock DJ, Goodman AD, Moser AB, Moser HW, Smith KD, Powers JM: Potential environmental and host participants in the early white matter lesion of adrenoleukodystrophy: morphologic evidence for CD8 cytotoxic T cells, cytolysis of oligodendrocytes, and CDI-mediated lipid antigen presentation. J Neuropathol Exp Neurol 200I, 60:1004-19.

\section{FlOOOPrime}

\section{RECOMMENDED}

66. Kemp S, Berger J, Aubourg P: X-linked adrenoleukodystrophy: clinical, metabolic, genetic and pathophysiological aspects. Biochim Biophys Acta 2012, I822:|465-74.

\section{FlOOOPrime}

\section{RECOMMENDED}

67. Powers JM, DeCiero DP, Ito M, Moser AB, Moser HW: Adrenomyeloneuropathy: a neuropathologic review featuring its 
noninflammatory myelopathy. I Neuropathol Exp Neurol 2000, 59: 89-102.

\section{FIOOOPrime}

68. Mar S, Noetzel M: Axonal damage in leukodystrophies. Pediatr Neurol 2010, 42:239-42.

69. van der Knaap MS, Pronk JC, Scheper GC: Vanishing white matter disease. Lancet Neurol 2006, 5:4I3-23.

70. Brück W, Herms J, Brockmann K, Schulz-Schaeffer W, Hanefeld F: Myelinopathia centralis diffusa (vanishing white matter disease): evidence of apoptotic oligodendrocyte degeneration in early lesion development. Ann Neurol 200I, 50:532-6.

71. Englund E, Brun A, Alling C: White matter changes in dementia of Alzheimer's type. Biochemical and neuropathological correlates. Brain 1988, I I I (Pt 6): 1425-39.

72. Boraschi D, Del Giudice G, Dutel C, Ivanoff B, Rappuoli R, GrubeckLoebenstein B: Ageing and immunity: addressing immune senescence to ensure healthy ageing. Vaccine 2010, 28:3627-3I.

73. Benilova I, Karran E, Strooper B de: The toxic $\mathbf{A} \beta$ oligomer and Alzheimer's disease: an emperor in need of clothes. Nat Neurosci 2012, I5:349-57.

\section{F1OOOPrime}

\section{RECOMMENDED}

74. Grant JL, Ghosn EEB, Axtell RC, Herges K, Kuipers HF, Woodling NS, Andreasson K, Herzenberg LA, Herzenberg LA, Steinman L: Reversal of paralysis and reduced inflammation from peripheral administration of $\beta$-amyloid in $\mathrm{THI}$ and $\mathrm{THI} 7$ versions of experimental autoimmune encephalomyelitis. Sci Transl Med 2012, 4:145ral05.

\section{FlOOOPrime} RECOMMENDED

75. Locatelli G, Wörtge S, Buch T, Ingold B, Frommer F, Sobottka B, Krüger M, Karram K, Bühlmann C, Bechmann I, Heppner FL,
Waisman A, Becher B: Primary oligodendrocyte death does not elicit anti-CNS immunity. Nat Neurosci 20 I2, I5:543-50.

FlOOOPrime

76. Ip CW, Kroner A, Bendszus M, Leder C, Kobsar I, Fischer S, Wiendl H, Nave K, Martini R: Immune cells contribute to myelin degeneration and axonopathic changes in mice overexpressing proteolipid protein in oligodendrocytes. J Neurosci 2006, 26:8206-16.

\section{FlOOOPrime}

\section{RECOMMENDED}

77. Kassmann CM, Lappe-Siefke C, Baes M, Brügger B, Mildner A, Werner HB, Natt O, Michaelis T, Prinz M, Frahm J, Nave K: Axonal loss and neuroinflammation caused by peroxisome-deficient oligodendrocytes. Nat Genet 2007, 39:969-76.

\section{FlOOOPrime
RECOMMENDED}

78. Wieser GL, Gerwig UC, Adamcio B, Barrette B, Nave K, Ehrenreich H, Goebbels S: Neuroinflammation in white matter tracts of CnpI mutant mice amplified by a minor brain injury. Glia 2013, 61:869-80.

79. Buch T, Heppner FL, Tertilt C, Heinen TJAJ, Kremer M, Wunderlich FT, Jung S, Waisman A: A Cre-inducible diphtheria toxin receptor mediates cell lineage ablation after toxin administration. Nat Methods 2005, 2:419-26.

80. Barnett $M H$, Prineas JW: Relapsing and remitting multiple sclerosis: pathology of the newly forming lesion. Ann Neurol 2004, 55:458-68.

\section{FlOOOPrime} RECOMMENDED

81. Salter MG, Fern R: NMDA receptors are expressed in developing oligodendrocyte processes and mediate injury. Nature 2005, 438: I |67-7|

82. Micu I, Jiang Q, Coderre E, Ridsdale A, Zhang L, Woulfe J, Yin X, Trapp BD, McRory JE, Rehak R, Zamponi GW, Wang W, Stys PK: NMDA receptors mediate calcium accumulation in myelin during chemical ischaemia. Nature 2006, 439:988-92.

\section{FlOOOPrime}

RECOMMENDED 